\title{
Estimation of vitrinite reflectance from well log data
}

\author{
Ali Kadkhodaie* and Reza Rezaee \\ Department of Petroleum Engineering, Curtin University, Perth, Western Australia
}

\begin{abstract}
Vitrinite reflectance $(V R)$ data provide important information for thermal maturity assessment and source rock evaluation. The current study introduces a practical method for vitrinite reflectance determination from sonic and resistivity logs. The main determinant factor of the method is $\triangle R R S$ which is defined as the separation between cumulative frequency values of resistivity ratio $(R R)$ and sonic log data. The values of $\triangle R R S$ range from -1 at ground level to +1 at bottom hole. The crossing point depth of the $D T$ and $R R$ cumulative frequency curves, where $\triangle R R S=0$, indicates the onset of oil generation window. From the surface (ground level) to the crossing point depth $\triangle R R S$ takes negative values indicating organic material diagenesis window. Below the crossing point depth $\triangle R R S$ turns into positive values showing thermally-mature organic matter within the catagenesis window.

Vitrinite reflectance measurements revealed strong exponential relationships with the calculated $\Delta R R S$ data. Accordingly, a new calibration chart was proposed for $V R$ estimation based on $\triangle R R S$ data. Finally, an equation is derived for vitrinite reflectance estimation from $\triangle R R S$ and geothermal gradient. The proposed equation works well in the event of having limited $V R$ calibration data.
\end{abstract}

Keywords: Vitrinite reflectance estimation, sonic log, resistivity ratio, $\Delta R R S$, geothermal gradient, shale gas

\section{Introduction}

Vitrinite reflectance is an important data for geochemical evaluation of source rocks and shale gas reservoir evaluation. Due to time, budget and sampling limitations, it is measured only on limited samples for a hydrocarbon field. To date, many studies have been conducted on estimation of different geochemical parameters from well log data (i.e. Schmoker, 1981; Passey et al., 1990; Rezaee et al., 2007; Kadkhodaie et al., 2009a,b; Sfidari et al., 2012; Altowairqi et al., 2015), while vitrinite reflectance estimation has received less attention. Hinds and Berg (1990) evaluated the thermal maturity of the Austin Chalk based on a combination of resistivity $\log \left(R_{t}\right)$, neutron and density logs. They concluded that true resistivity log reading is low in the thermally immature zone, increases to the highest in the peak-oil generation window and

\footnotetext{
* Corresponding author: Tel/Fax: +61892669366

Email addresses: ali.kadkhodaie@curtin.edu.au (Ali Kadkhodaie), r.rezaee@curtin.edu.au (Reza Rezaee)
} 
decreases to moderate values in the expulsion window. McTavish (1994) applied estimated source rock maturity by looking at well log signatures in mature zones. Zhao (2004) studied the thermal maturation and physical properties of Barnett Shale in the Fort Worth Basin. Later, Zhao et al. (2007) introduced a method for assessment of thermal maturity from well logs analysis. Lecompte and Hursan (2010) re-arranged the delta Log R equation (Passey et al., 1990) to solve for the level of maturity and correlated it to vitrinite reflectance. Afterward, they introduced a method to determine kerogen density from log and core data. They showed how changes in kerogen density and delta log $\mathrm{R}$ relate to the thermal maturity and predicted whether the source rock will generate oil, gas or condensate. Labani and Rezaee (2013) proposed an index for determining thermal maturity of the gas shale formation by using neutron porosity, density, and volumetric photoelectric adsorption.

The current study proposes a practical method for quantifying vitrinite reflectance from sonic and resistivity logs. A new parameter termed $\triangle R R S$ will be introduced which is strongly correlated to thermal maturity of subsurface formations. The approach of calculating $\triangle R R S$ is an important contribution to derive an equation for vitrinite reflectance estimation.

\section{Developing a new method for vitrinite reflectance estimation}

\subsection{Key fundamentals}

The main idea behind this research comes from this hypothesis that "well log data respond to the thermal maturation of organic matter”. The hypothesis triggers the idea of finding a way to estimate vitrinite reflectance from well logs. Expulsion of hydrocarbons out of a mature source rock will affect both sonic and resistivity log readings. Assume two different source rocks $A$ and $B$. Both source rocks have the same lithology, organic matter type and total organic carbon content. Source rock $A$ has reached oil window and hydrocarbons are cooked out of that, while source rock $B$ is still in diagenesis window and has not produced any oil and gas. It is expected that both $D T$ and resistivity log readings in source rock $A$ to be higher than source rock $B$. This is due to the physical fundamental that hydrocarbons increase the sonic transit time and cause resistance against electrical currents. Although, several subsurface rock and fluid heterogeneities may complicate the logging tool responses but following such general trends lead us towards establishing new relationships for vitrinite reflectance estimation.

Since maturation of organic-rich rock leads to the generation of oil and gas out of a source rock which can, in turn, leads to an increase in hydrocarbons saturation, resistivity ratio $(R R)$ parameter was preferred to be used rather than deep resistivity log. Resistivity ratio $\left(R_{o} / R_{t}\right)$ is defined as the ratio of $100 \%$ water-filled rock's resistivity $\left(R_{o}\right)$ to true formation resistivity $\left(R_{t}\right)$. As shown below, it bears the closest meaning to formation water saturation. 
If formation factor $(F)$ in Archie equation (Eq. 1) is substituted with $F$ in Eq. 2, then a simplified form of Archie’s equation will be determined for water saturation calculation (Eq. 3).

$S_{w}^{n}=\frac{F \cdot R_{w}}{R_{t}}$

$F=\frac{R_{o}}{R_{w}}$

$S_{w}^{n}=\frac{R_{o}}{R_{t}}$

Therefore, resistivity ratio, which somehow highlights fluid saturation, is a stronger attribute for maturity assessment rather than the solitary use of deep resistivity log. Having the above-mentioned physics overruled in subsurface conditions, some relationships between sonic and resistivity ratio versus burial depth can be established for thermal maturity assessment. Generally, thermal maturity increases by increasing burial depth. Cumulative frequency of sonic $\left(D T_{\text {cum }}\right)$ and resistivity ratio $\left(R R_{\text {cum }}\right)$ versus depth seems to be a practical way to relating thermal maturity to well logs. All these provide a forum to introduce $\Delta R R S$, a newly derived maturity assessment parameter, which is discussed in the next section.

\section{2. $\triangle R R S$ : the separation between cumulative sonic and resistivity ratio logs}

As mentioned in the previous section, sonic log and resistivity index are two strong parameters relating to the thermal maturation of source rocks. As shown in Figure 1, in a cumulative plot of $R R$ and $D T$ logs versus depth a separation is seen between them which is strongly correlated to the thermal maturation of source rocks. One important point to be considered is the opposite direction of x-axis $R R_{\text {cum }}$ and $D T_{\text {cum }}$ axis. It was discussed in section 2.1 that when oil and gas are generated out of a mature source rock an increase in hydrocarbons saturation is expected to take place. As resistivity ratio is somehow related to water saturation, the quantity of $1-R R$ will make more sense as an indication of hydrocarbons saturation. That is why $R R$ and $D T$ take opposite directions in Figure 1. Accordingly, an increase in both $D T_{\text {cum }}$ and $R R_{\text {cum }}$ as a result of thermal maturation will cause a separation between them. This separation is named $\Delta R R S$. The letters "RR" and " $S$ " in $\triangle R R S$ stand for resistivity ratio and sonic log, respectively. $\triangle R R S$ can simply be calculated by using Eq. 4.

$\Delta R R S=D T_{\text {Cum }}-\left(1-R R_{\text {Cum }}\right) \quad($ Eq. 4$)$

$\triangle R R S$ is a unitless parameter taking values from -1 at ground level to +1 at bottom hole. The crossing point depth of $D T_{\text {Cum }}$ and $R R_{\text {Cum }}$ curves indicates the onset of oil generation window. From surface (ground level) to the crossing point depth $\triangle R R S$ takes negative values indicating diagenesis window. Below the crossing point depth $\triangle R R S$ turns into positive values showing mature organic matter in catagenesis window. In the 
catagenesis window the higher $\triangle R R S$ separation indicates the higher maturation, while maturity decreases as $\triangle S R R$ separation increases in the diagenesis window. Two examples of calculating $\Delta R R S$ at depth points of $300 \mathrm{~m}$ and $1700 \mathrm{~m}$ are shown in Figure 1. The calculated $\triangle R R S$ values are important data for making relationships with laboratory measured vitrinite reflectance data.

The computational steps of $\triangle R R S$ are summarized as follows:

Step 1: Quality control $D T$ and $R_{t}$ logs for noise, de-spiking, log tails, out of range values, etc.

Step 2: Replace the null values or any missing data with average sonic transit time and resistivity of that layer.

Step 3: Calculate $R R$ using $R_{o} / R_{t}$ ratio; $R_{o}$ is determined from the reading of deep resistivity log in wet-zones where rocks are fully saturated with water.

Step 4: Add up all $D T$ and $R R$ data point from the surface to the bottom hole depth,

Step 5: Find frequency of sonic $\log f(D T)$ and resistivity ratio $f(R R)$ at each depth point. To do this, simply divide $D T$ and $R R$ values at each depth point by the summation values obtained in step 4,

Step 6: Calculate the cumulative frequency values of $f(D T)$ and $f\left(R_{R R}\right)$,

Step 7: Calculate $\Delta R R S=D T_{\text {Cum }}-\left(1-R R_{\text {Cum }}\right)$

It should be point out that calculation of $\triangle R R S$ needs a continuous $D T$ and deep resistivity log from the surface to bottom hole. As normally logging data are not available for surface formations, one needs to extrapolate $D T$ and $L L D$ to the surface or assume average values for missing log intervals considering their lithology, fluids, and compaction.

\subsection{Relationships between vitrine reflectance and $\Delta R R S$}

The relationships between $\triangle R R S$ and laboratory measured vitrinite reflectance were investigated. A set of well logs including sonic and resistivity logs together with 113 vitrinite reflectance measurements from 11 wells including Sue-1, Wicher Range-1, Walyering-1, Crystal Creek-1, Wicherina-1, Eneabba-1, Cycas-1, Bindi-1, Crismon Lake-1, Yardarino-1 and Woolmulla-1 were used to examine the performance of the proposed methodology (Table 1). The studied well are situated the Canning and Perth basins, Western Australia. Their geothermal gradient is variably ranging from 1.96 to $3.80{ }^{\circ} \mathrm{C} / 100 \mathrm{~m}$. Well logs were checked and quality controlled for washout, outliers, log tails, spikes and environmental effects. Depth matching was carried out to ensure the correct reading of each VR sample against its corresponding sonic and resistivity logs. Finally, $\triangle R R S$ was calculated for each individual well. Several cross-plots were prepared to investigate any possible correlation between $V R$ and $\triangle R R S$ (Figures 2a-k) for each individual well. The outcome is interesting and as is seen in Figure 2, a strong exponential correlation exists between vitrinite reflectance and 
$\triangle R R S$. In Figure 3a, a scatter-plot of $V R$ versus $\triangle R R S$ for all studied wells is illustrated. Accordingly, a calibration chart can be proposed to formulate vitrinite reflectance to $\Delta R R S$ values (Figure $3 b$ ). As is seen, the calibration chart covers different ranges of $V R$ values ranging from $0.31 \%$ to $3.82 \%$. Tha application of Figure $3 b$ is by having some limited $V R$ data plotted on this calibration chart, an appropriate equation can be chosen for $V R$ estimation. The chosen equation is then applied throughout the borehole to estimated $V R$ based on a previously calculated continuous log of $\triangle R R S$.

\subsection{Vitrinite reflectance estimation}

In this study a practical equation is derived for vitrinite reflectance determination from well log data. When there are some measured $V R$ data for an area, then the calibration chart presented is Figure 3b can easily be employed to get the suitable equation to estimate vitrinite reflectance from $\Delta R R S$ data. The problem is with the cases for which there are no or scarce calibration $V R$ data. To tackle such a problem, the $\Delta R R S$ separation between $D T_{\text {Cum }}$ and $R R_{\text {Cum }}$ needs to be calibrated with a second parameter in favour of laboratory data. As shown in Figure 3b, each equation used to estimate vitrinite reflectance has an exponential form as follows.

$$
R o=A e^{B \times \Delta R R S} \quad(\mathrm{Eq} .5)
$$

As is seen from Eq. 5, the coefficient $A$ and the exponent $B$ are two main parameters which can somehow be related to thermal maturity. Having a good approximation of $A$ and $B$ parameters will aid in a satisfactory estimation of $V R$. Further investigations revealed that geothermal gradient is a determinant factor affecting both $A$ and $B$ coefficients in Eq. 5. The parameters $A$ and $B$ pertaining to each $V R-\triangle R R S$ exponential equation (Figures 2a-k) along with their geothermal gradient (GG) are summarized in Table 2. As shown in Figure 4 direct relation is observed between exponent $B$ and geothermal gradient $(B=0.7143 G G-1.1593)$. However, such a relationship was too complex for parameter $A$ of the Eq. 5. Taking an average of $A$ parameter and replacing $B$ with $0.7143 G G-1.1593$ in Eq. 5, an equation can be obtained as follows.

$V R(\%)=0.5615 e^{(0.7143 G G-1.1593) \Delta R R S}$

Having the geothermal gradient of the study area (in ${ }^{\circ} \mathrm{C} / 100 \mathrm{~m}$ ) and $\triangle R R S$ calculated from sonic and resistivity logs, one can estimate vitrinite reflectance from Eq. 6 without any need to calibration data.

\section{Results and discussion}

The results of applying the proposed calibration chart (Figure 3b) for estimation of vitrinite reflectance in the studied wells of the Canning and Perth basins are shown in Figure 5a. As illustrated, there is a high correlation coefficient of 0.92 between measured and estimated VR data. Having some laboratory measured 
$V R$ data and calculating their corresponding $\triangle R R S$ from well logs, an appropriate equation can be chosen based on Figure 3b.

In the event that the calibration data lie on the different curves shown in Figure 3b, a cut-off should be defined based on $\triangle R R S$ value to use the appropriate equation for each $\Delta R R S$ range.

It is worth mentioning that the calibration chart covers almost all ranges of vitrinite reflectance data ranging from $0.31 \%$ to $3.82 \%$. It is expected that the chart works effectively in many other similar formations. However, one can derive a suitable equation for a certain formation by plotting the well log derived $\Delta R R S$ versus laboratory measured VR data in Excel sheets and finding their relationship.

The results of applying the newly introduced equation (Eq. 6) are displayed in Figure 5b. As is seen, the correlation coefficient of 0.85 is obtained between measured and estimated VR estimation data. Such a satisfactory result indicates the efficiency of the equation 6 in the case of not having access to calibration $V R$ data. VR can easily be estimated from Eq. 6 by using the geothermal gradient of the study area (in ${ }^{\circ} \mathrm{C} / 100 \mathrm{~m}$ ) and $\triangle R R S$ calculated from sonic and resistivity logs.

The geothermal gradient introduced in Eq. 6 works in favour of calibration data. It should be mentioned that prior to introducing of the geothermal gradient parameter, attempts have been made to relate the crossing point depth of $R R_{\text {Cum }}$ and $D T_{C} u m$ curves to the exponent $B$ in Eq. 5. The attempts, however, were found to be unsatisfactory. Considering the results shown in Table 2 and Figure 4, geothermal gradient showed a stronger relationship with the maturity exponent $B$. The reason for this can be attributed to effect of uplift and erosion on the organic material maturity trend with depth. Uplift and erosion can make complexity in thermal maturity trends causing difficulty in establishing further correlations. Geothermal gradient, however, regardless of such complexities increase as burial depth increases. This has to be noted for this method we use current geothermal gradient that may be different from the original one. If available, correct geothermal gradient value will result in a better estimation of $V R$ values.

Another important merit of $\triangle R R S$ method is its application in determining the onset of oil generation window. It was observed that the crossing point depth in cumulative $R R$ and sonic log plots indicates the onset of generation oil window. Depth profiles of cumulative $D T$ and $R R$ logs for sample wells Cycas-1, Walyering-1, Crimson Lake-1 and Yardarino-1 are shown in Figure 6a-d, respectively. Measured vitrinite reflectance data are plotted next to each composite diagram as a measure of maturity. As is seen, the crossing point of $R R_{\text {Cum }}$ and $D T_{\text {Cum }}$ matches well with the onset of catagenesis window occurring at $V R \sim 0.5-0.6 \%$.

Calculating $\triangle R R S$ requires continues sonic and water resistivity logs measured from the surface to bottom hole. As normally logging data are not available for surface formations, one needs to assume average values of $D T$ and $L L D$ for the missing log intervals. For example, if well logging date are recorded from 500- 
$3000 \mathrm{~m}$, then $\triangle R R S$ should be calculated from sea level (elevation=0) to 3000 meters. Having a shaly interval from ground level to 500 meters below subsea, one can assume the average value of $L L D=10 \Omega . \mathrm{m}$ and $D T=70 \mu \mathrm{s} / \mathrm{f}$ for this layer. The alternative way is to extrapolate $D T$ and $L L D$ to the surface if their response show some trends with depth increase.

It was observed that there is an exponential relationship between $\triangle R R S$ and $V R$ meaning that the rate of geochemical reactions increases exponentially with increasing temperature. This is consistent with the Lopatin’s fundamental thermal maturity rule (Lopatin, 1971) stating “for every 10-degree centigrade increase in subsurface temperature the rate of geochemical reactions will double”.

\section{Conclusions}

In this research, a calibration chart and an effective equation were proposed for vitrinite reflection determination based upon sonic and resistivity logs. The results show that in the event of having sufficient laboratory $V R$ data the proposed calibration chart can effectively be used to choose an appropriate $\Delta R R S-V R$ correlation. In the case of not having access to laboratory measured VR data, the newly derived equation can effectively estimate vitrinite reflectance from the geothermal gradient and well log derived $\Delta R R S$. Another important finding of this research is to relate the oil generation window to the $\triangle R R S$ parameter. It was observed that the crossing point depth of $R R_{\text {Cum }}$ and $D T_{\text {Cum }}$ curves in almost all studied wells corresponds to the onset of oil generation window. The depth for which $\triangle R R S=0$ is associated with the vitrinite reflectance values of about $0.5-0.6 \%$ confirming the onset of catagenesis window.

\section{References}

Altowairqi, Y., R. Rezaee, B. J. Evans, and M. Urosevic. 2015."Shale elastic property relationships as a function of total organic carbon content using synthetic samples. ”Journal of Petroleum Science and Engineering 133: 392-400.

Hinds, G.S., Berg, R.R., 1990. Estimating organic maturity from well Logs, Upper Cretaceous Austin Chalk, Texas Gulf Coast. Gulf Coast Association of Geological Societies Transactions 40, 295-300.

Kadkhodaie, A., Rezaee, M.R., Rahimpour-Bonab, H., 2009a. A Committee Neural Network for Prediction of Normalized Oil Content from Well Log Data: an Example from South Pars Gas Field, Persian Gulf. Journal of Petroleum Science and Engineering 65, 23-39.

Kadkhodaie, A., Rahimpour-Bonab, H., Rezaee, M.R., 2009b. A Committee Machine with Intelligent Systems for Estimation of Total Organic Carbon Content from Petrophysical Data: An Example from the Kangan and Dalan Reservoirs in South Pars Gas Field, Iran. Computers \& Geosciences 35, 459-474 
Labani, M.M., Rezaee, R., 2013. Thermal maturity estimation of gas shale layers from conventional well log data: a case study from Kockatea Shale and Carynginia Formation of Perth Basin, Australia, in SPE Asia Pacific Oil and Gas Conference and Exhibition, Oct 22-24 2012, pp. 1-10. Perth, Australia: SPE.

Lecompte, B., Hursan, G., 2010. Quantifying source rock maturity from logs: how to get more than TOC from Delta Log R. SPE Annual Technical Conference and Exhibition, 19-22 September, Florence, Italy

McTavish, R.A., 1996. Applying wireline logs to estimate source rock maturity. Oil and Gas Journal 7; 7679.

Lopatin, N.V., 1971. Temperature and geologic time as factors in coalification. Akad. Nauk. SSSR Izv. Serv. Geol. 3, 95-106

Passey, Q. R., Creaney, S., Kulla, J. B., Moretti, F. J., Stroud, J. D., 1990. Practical model for organic richness from porosity and resistivity logs. AAPG Bulletin 74, 1777-1794

Rezaee, R., R. M. Slatt, and R. F. Sigal. 2007.“Shale Gas Rock Properties Prediction using Artificial Neural Network Technique and Multi Regression Analysis, anexample from a North American Shale Gas Reservoir.” In 19th International Geophysical Conference and Exhibition: Exploration and Beyond, Nov 18, 2007, Perth, Australia: CSIRO Publishing.

Sfidari, E., Kadkhodaie, A, Najjari, S., 2012. Comparison of intelligent and statistical clustering approaches to predicting total organic carbon using intelligent systems. Journal of Petroleum Science and Engineering 86-87, 190-205.

Schmoker, 1981. Determination of Organic-Matter Content of Appalachian Devonian Shales from GammaRay Logs: American Association of Petroleum Geologists Bulletin 65, 1285-1298

Zhao, H., 2004, Thermal maturation and physical properties of Barnett Shale in the Fort Worth Basin, north Texas (abs.): AAPG Annual Meeting Program, v. 13, p. A154.

Zhao, H., Givens, N.B., Curtis, B., 2007. Thermal maturity of the Barnett Shale determined from well-log analysis. AAPG Bulletin 91 (4), 535-549. 


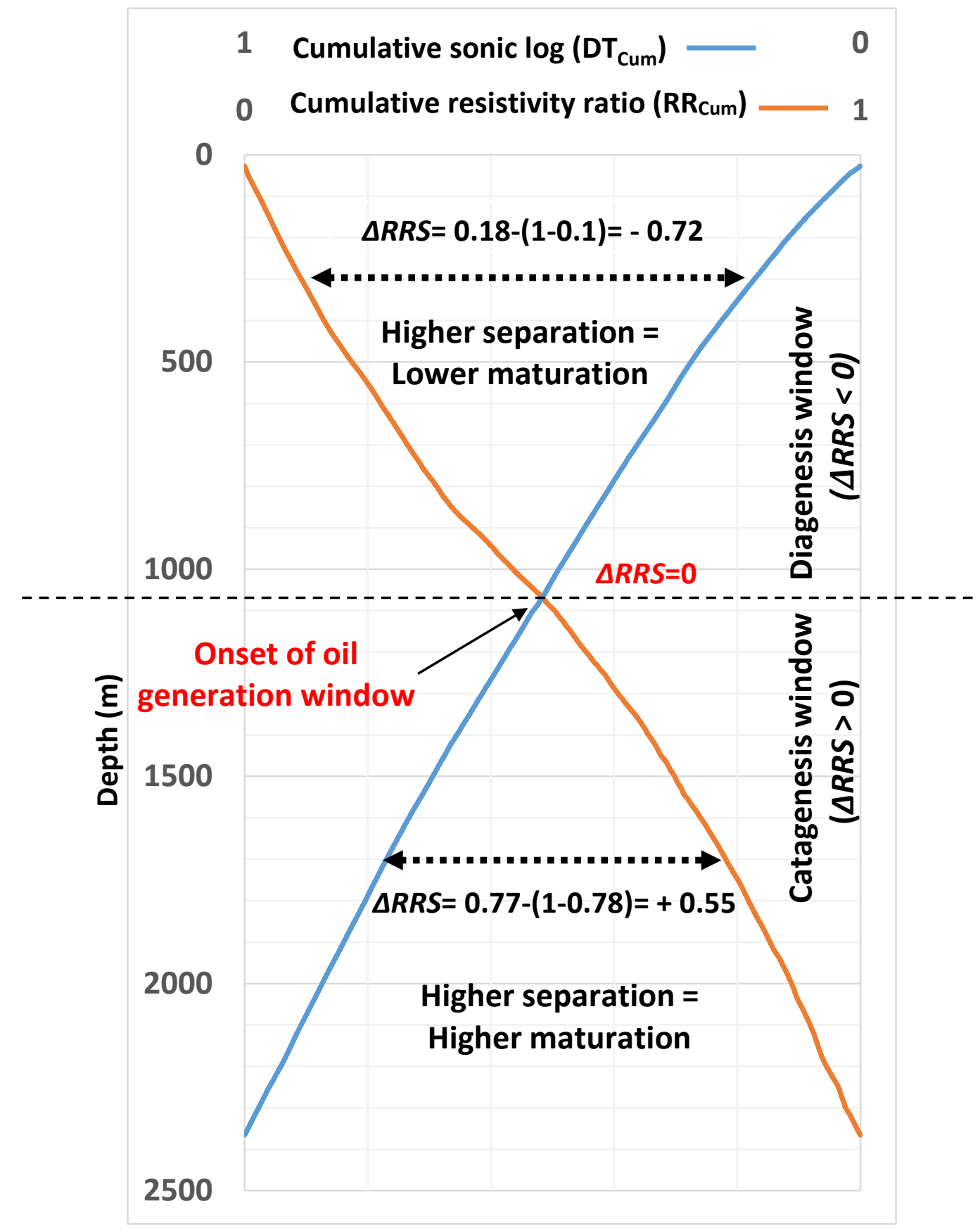

Fig. 1. Graphical illustration showing the concept of $\triangle R R S$. It is defined as the separation between cumulative frequency values of resistivity ratio and sonic data $\left(\triangle R R S=D T_{\text {Cum }}-\left(1-R R R_{\text {Cum }}\right)\right)$. Crossing point depth of two curves $(\triangle R R S=0)$ indicates onset of oil generation window. From surface (ground level) to crossing point depth $\triangle R R S$ takes negative values indicating diagenesis window. Below crossing point depth $\triangle R R S$ turns into positive values showing mature organic matter in catagenesis window. Within catagenesis window, the higher the separation is the higher the maturation will be and it is vice versa in the diagenesis window. Two examples of calculating $\triangle R R S$ at depth points of $300 \mathrm{~m}$ and $1700 \mathrm{~m}$ are illustrated on the plot. 

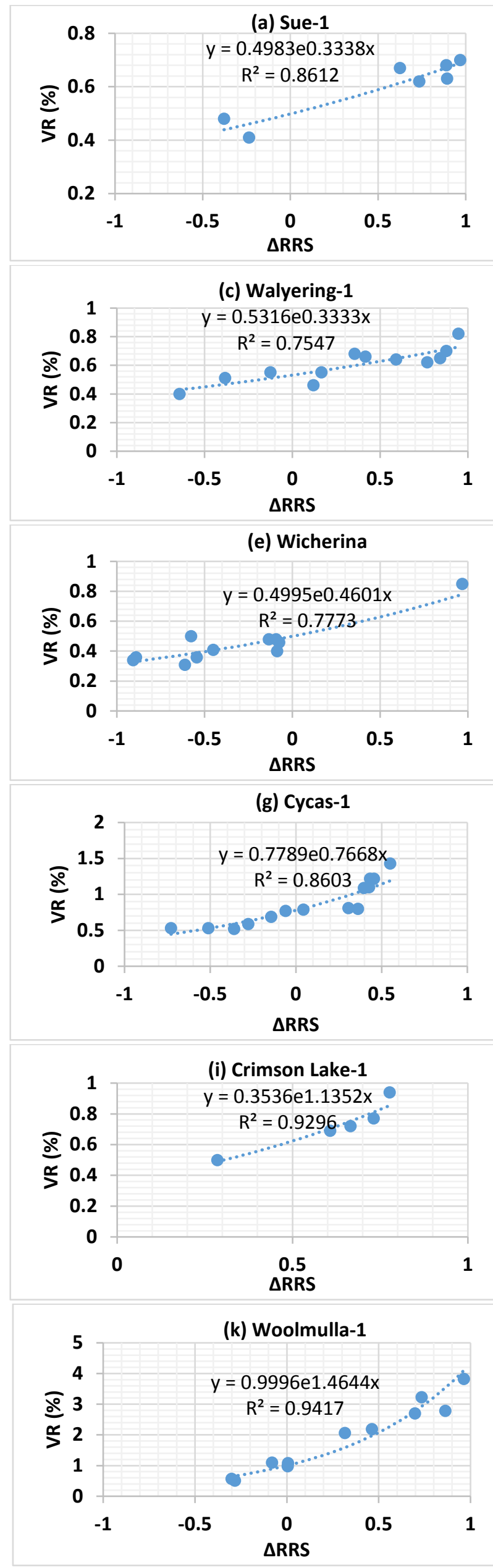
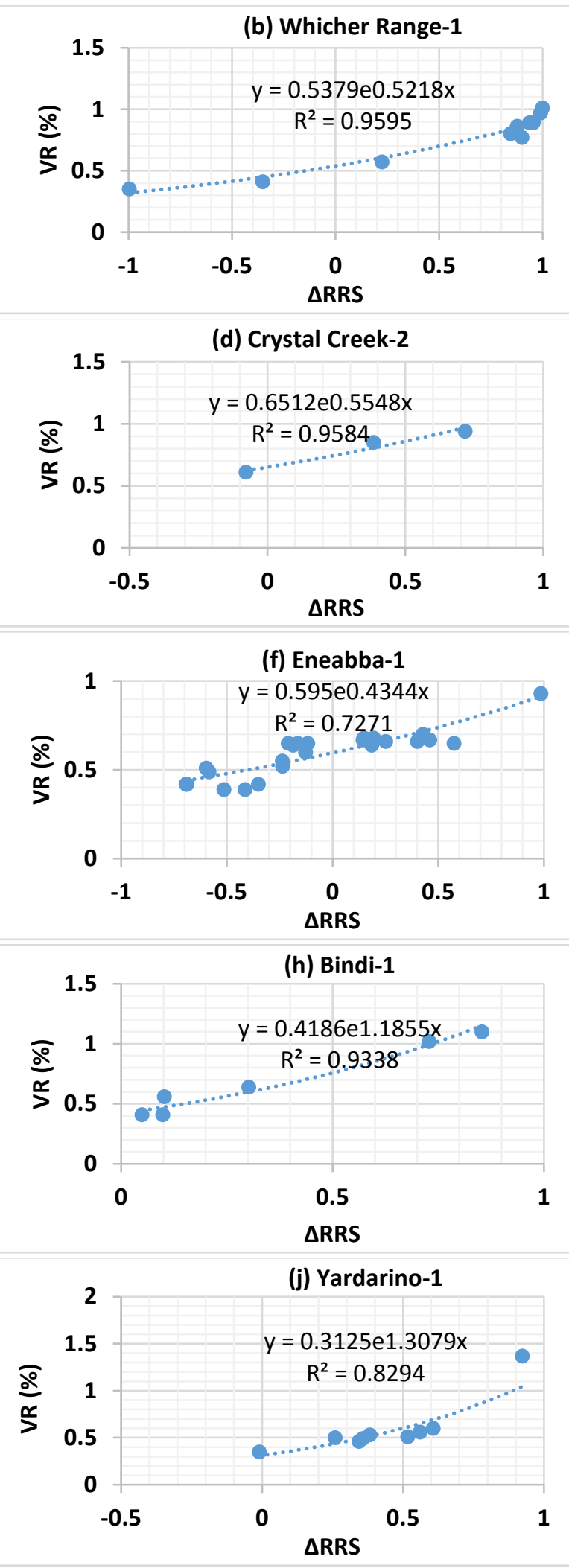

Fig. 2. Crossplots showing the relationships between vitrinite reflectance $(V R)$ and $\triangle R R S$ in wells Sue-1 (a), Whicher Range 1(b), Walyering1 (c), Crystal Creek-1 (d), Wicherina-1 (e), Eneabba-1 (f), Cycas-1 (g), Bindi (h), Crimson lake-1 (i), Yardarino-1 (j) and Woolmulla-1 (k). As is seen, a strong exponential correlation exists between $V R$ and $\triangle R R S$. 

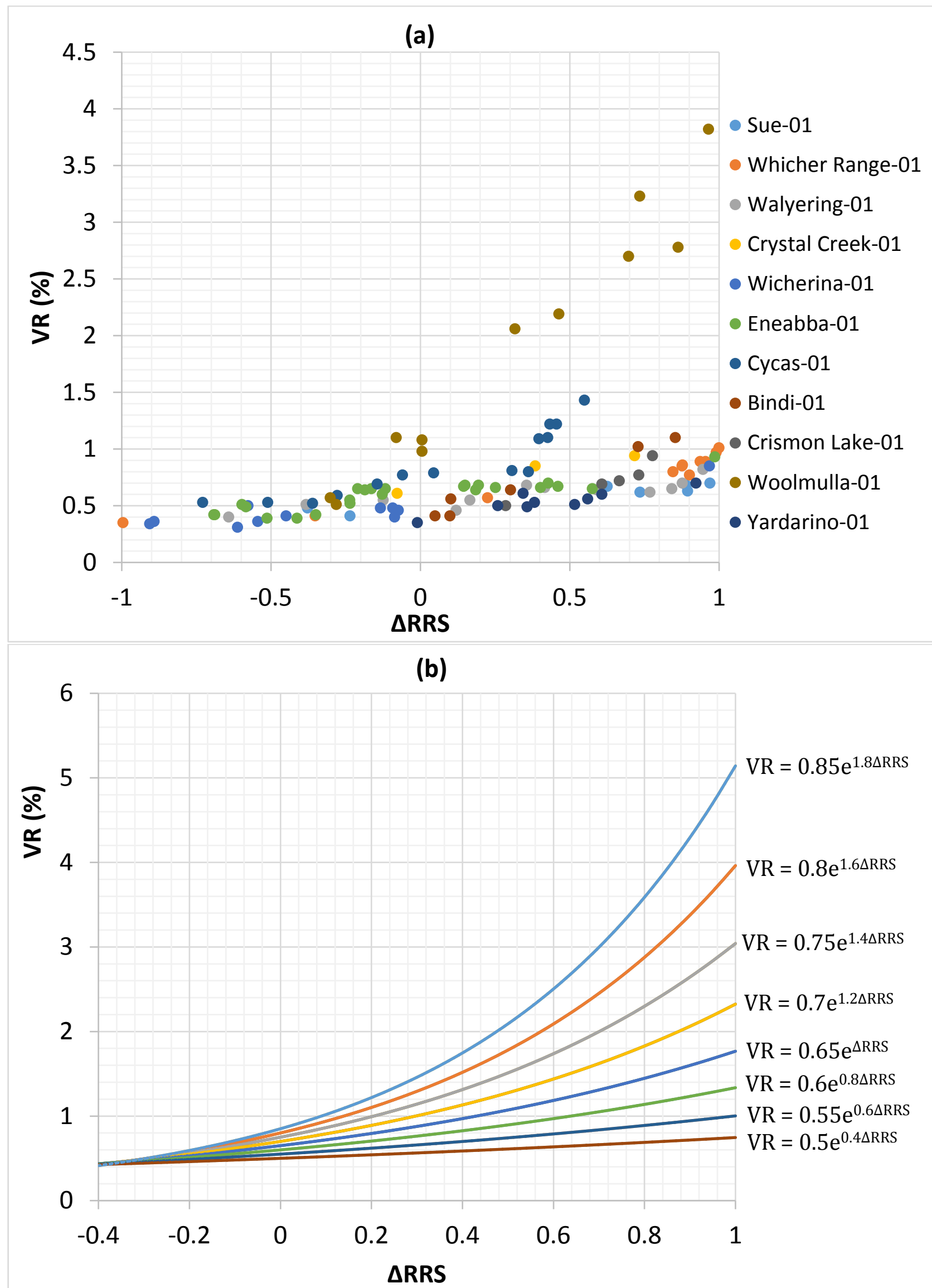

Fig. 3. A scatter-plot of VR versus $\triangle R R S$ for all studied wells in Canning and Perth basins (a). The proposed calibration chart to choose appropriate equation for vitrinite reflectance estimation from $\triangle R R S$ data. 


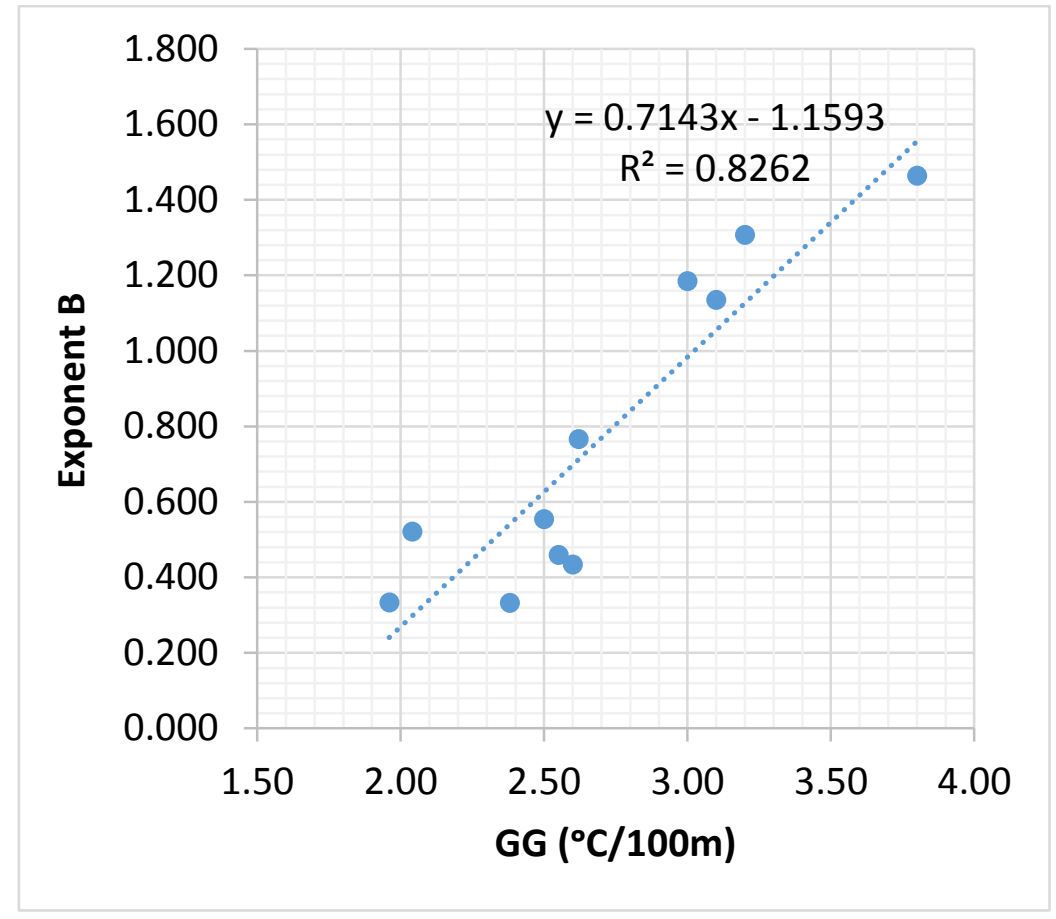

Fig. 4. Crossplot showing the relation between exponent $B$ in $V R$ estimation equation and geothermal gradient. 

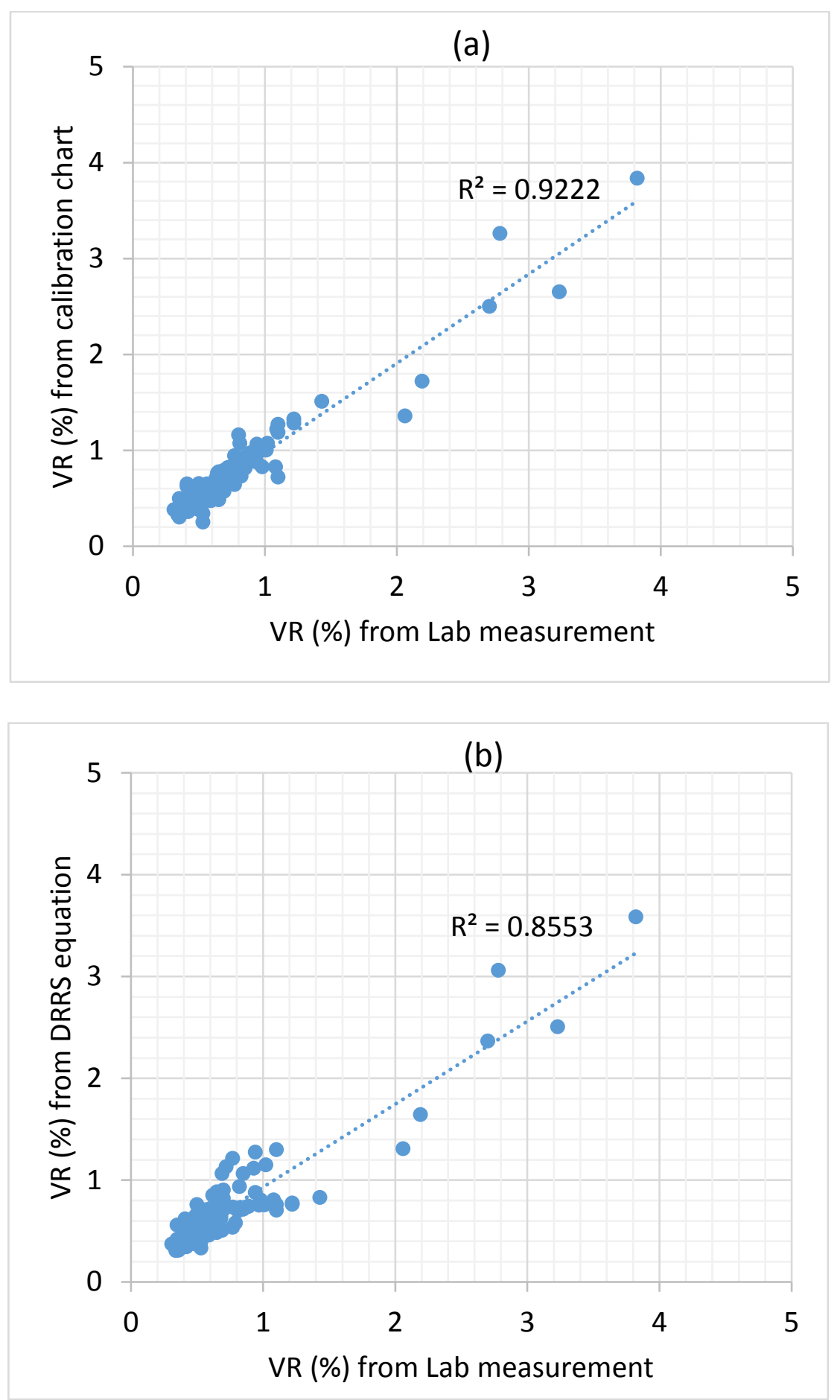

Fig. 5. Crossplots showing the correlation coefficient between measured and estimated vitrinite reflectance by using calibration chart proposed in Figure 3b (a) and introduced equation (b). 

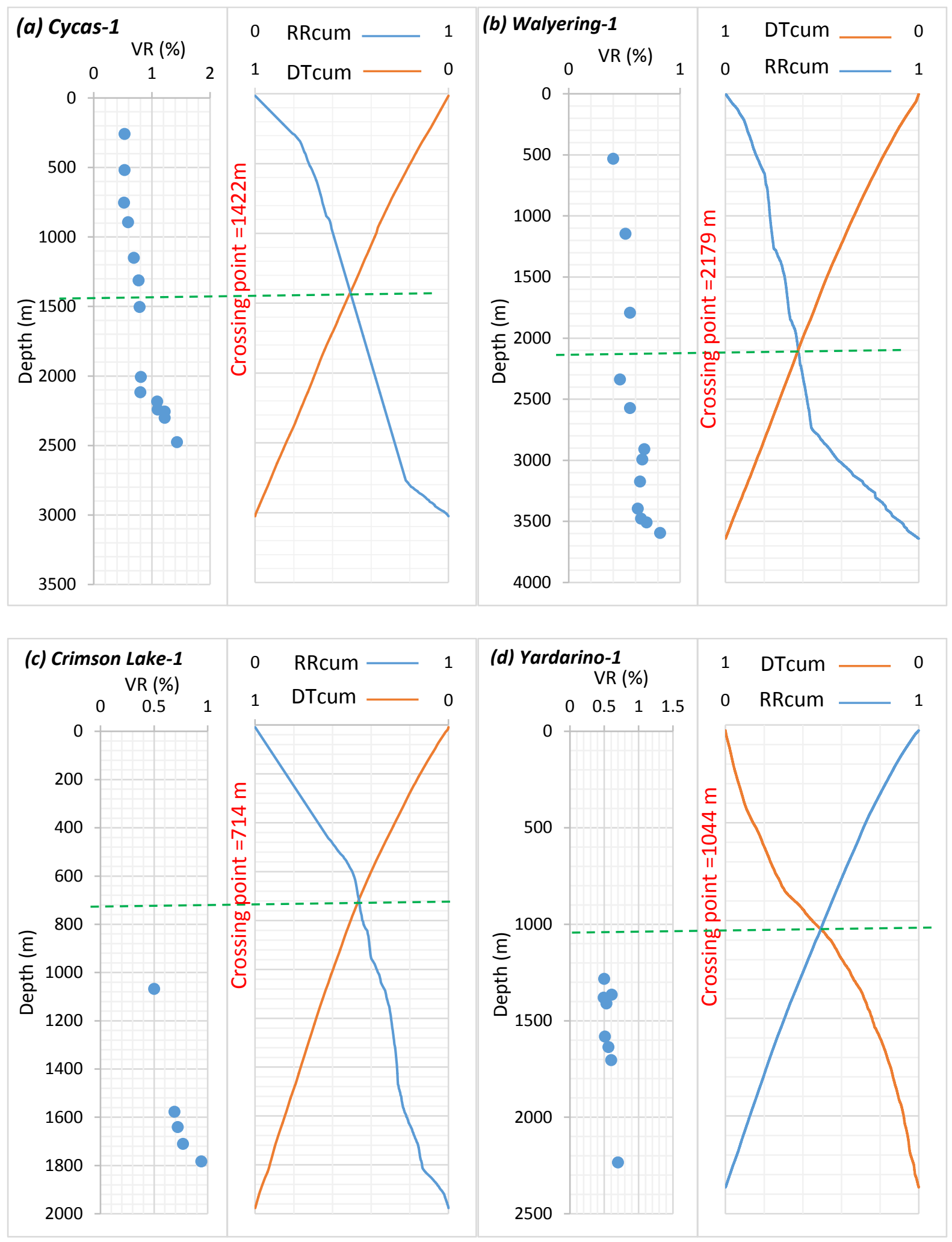

Fig. 6. Depth profiles of cumulative sonic and resistivity ratio logs for wells Cycas-1 (a), Walyering-1 (b), Crimson Lake-1 (c) and Yardarino-1 (d). Measured vitrinite reflectance data are plotted next to each composite diagram as a measure of maturity. As is seen, the crossing point of $R R_{\text {Cum }}$ and $D T_{\text {Cum }}$ matches well with the onset of oil generation window occurring at VR 0.5-0.6\%. 